\title{
Guanosine reduces apoptosis and inflammation associated with restoration of function in rats with acute spinal cord injury
}

\author{
Shucui Jiang • Farid Bendjelloul • Patrizia Ballerini • \\ Iolanda D'Alimonte · Elenora Nargi • Cai Jiang • \\ Xinjie Huang • Michel P. Rathbone
}

Received: 21 June 2007 / Accepted: 22 August 2007 / Published online: 25 September 2007

(C) Springer Science + Business Media B.V. 2007

\begin{abstract}
Spinal cord injury results in progressive waves of secondary injuries, cascades of noxious pathological mechanisms that substantially exacerbate the primary injury and the resultant permanent functional deficits. Secondary injuries are associated with inflammation, excessive cytokine release, and cell apoptosis. The purine nucleoside guanosine has significant trophic effects and is neuroprotective, antiapoptotic in vitro, and stimulates nerve regeneration. Therefore, we determined whether systemic administration of guanosine could protect rats from some of the secondary effects of spinal cord injury, thereby reducing neurological deficits. Systemic administration of guanosine ( $8 \mathrm{mg} / \mathrm{kg}$ per day, i.p.) for 14 consecutive days, starting $4 \mathrm{~h}$ after moderate spinal cord injury in rats, significantly improved not only motor and sensory functions, but also recovery of bladder function. These improvements were associated with reduction in the inflammatory response to injury, reduction of apoptotic cell death, increased sparing of axons, and preservation of myelin. Our data indicate that the therapeutic action of guanosine probably results from
\end{abstract}

S. Jiang $(\varangle) \cdot$ F. Bendjelloul

Department of Surgery (Neurosurgery), McMaster University,

Health Sciences Centre, 4N71B, 1200 Main Street West,

Hamilton L8N $3 Z 5$ ON, Canada

e-mail: jiangs@mcmaster.ca

C. Jiang $\cdot$ X. Huang $\cdot$ M. P. Rathbone

Department of Medicine (Neurology), McMaster University,

Health Sciences Centre, 4N71B, 1200 Main Street West,

Hamilton L8N $3 Z 5$ ON, Canada

P. Ballerini · I. D'Alimonte · E. Nargi

Department of Biomedical Sciences,

Universita Degli Studi “G. D’Annunzio”, University Of Chieti,

Nuovo Polo Didattico, Via Dei Vestini, 31,

Chieti 66013, Italy reducing inflammation resulting in the protection of axons, oligodendrocytes, and neurons and from inhibiting apoptotic cell death. These data raise the intriguing possibility that guanosine may also be able to reduce secondary pathological events and thus improve functional outcome after traumatic spinal cord injury in humans.

Keywords Apoptosis · Cell death · Glia $\cdot$ Guanosine . Immunohistochemistry · Inflammation . Locomotor and sensory function $\cdot$ Myelin . Spinal cord injury

$\begin{array}{ll}\text { Abbreviations } \\ \text { BBB } & \text { Basso-Beattie-Bresnahan locomotor rating scale } \\ \text { bFGF } & \text { basic fibroblast growth factor } \\ \text { cAMP } & \text { cyclic adenosine monophosphate } \\ \text { CSF } & \text { cerebral spinal fluid } \\ \text { dUTP- } & \text { 2'-deoxyuridine 5'-triphosphate } \\ \text { biotin } & \\ \text { FITC } & \text { fluorescein isothiocyanate } \\ \text { FOR } & \text { foot orienting response } \\ \text { GFAP } & \text { glial fibrillary acidic protein } \\ \text { HLPR } & \text { hind limb placing response } \\ \text { i.p. } & \text { intraperitoneal } \\ \text { IPT } & \text { inclined plane test } \\ \text { LUT } & \text { lower urinary tract } \\ \text { MAP } & \text { mitogen-activated protein } \\ \text { MAPK } & \text { mitogen-activated protein kinase } \\ \text { MBP } & \text { myelin basic protein } \\ \text { NGF } & \text { nerve growth factor } \\ \text { NT-3 } & \text { neurotrophin-3 } \\ \text { OFWT } & \text { open field walking test } \\ \text { PBS } & \text { phosphate-buffed saline } \\ \text { PFA } & \text { paraformaldehyde } \\ & \end{array}$




$\begin{array}{ll}\text { PI-3-K } & \text { phosphatidylinositol 3-kinase } \\ \text { PKB } & \text { protein kinase B } \\ \text { SCI } & \text { spinal cord injury } \\ \text { SEM } & \text { standard error of the mean } \\ \text { TdT } & \text { terminal deoxynucleotidyl transferase } \\ \text { TNF- } & \text { tumor necrosis factor-alpha } \\ \text { alpha } & \\ \text { TUNEL } & \text { terminal deoxynucleotide transferase dUTP nick } \\ & \text { end labeling }\end{array}$

\section{Introduction}

Spinal cord injury (SCI) occurs in an instant, but its devastating effects last a lifetime at huge personal and economic cost [1]. The spinal cord conveys both afferent sensory and efferent motor information, so disruption of spinal cord function results not only in motor paralysis but also sensory and autonomic impairment distal to the injury $[2,3]$. Sensory dysfunction contributes to the generation of pressure sores that, like bladder impairment, are a major source of morbidity and even mortality in those with spinal cord injury [4].

Restoration of function in longstanding spinal cord injuries is poor, although some limited functional restoration has been reported [5]. Therefore, there is much interest in reducing the extent of the initial damage from traumatic spinal cord injury in the acute phase. Trauma often results in primary damage resulting from mechanical disruption of the nerve axons in the spinal cord that is not amenable to neuroprotective therapy. However, secondary pathological changes involving cascades of biochemical, molecular, and cellular changes can produce even more extensive damage, and these changes are potentially susceptible to therapeutic intervention with neuroprotective agents [3, 6]. Thus, pathological changes occur from the moment of injury and continue for years afterwards and have been divided into three phases: an acute phase, a phase of secondary tissue loss, and a chronic phase $[3,6]$.

In the acute phase, which starts at the moment of injury and extends over the first few days, numerous pathological processes begin. Mechanical injury induces an immediate change in neuronal tracts at the moment of impact, blood flow is reduced, creating substantial ischemic necrosis [7, 8] and a cascade of pathophysiological processes rapidly follows mechanical trauma to the spinal cord, resulting in secondary neuronal damage that can significantly exacerbate the original injury [9]. Traumatic injury to the spinal cord also leads to a strong inflammatory response, with the recruitment of peripherally derived inflammatory cells, including macrophages [10]. Damage to the spinal cord also results in extensive cell proliferation in and around the epicenter, many of which are microglia and macrophages.
This acute inflammatory response at the site of the initial lesion is at least partly responsible for secondary spinal cord pathology [11-13]. The inflammatory cells (particularly macrophages/microglia) can mediate tissue damage by producing a variety of cytotoxic factors including interleukins [14], tumor necrosis factor-alpha (TNF-alpha) [15], and reactive nitrogen species [13, 16-18]. Neuronal and oligodendroglial cell loss is apparent in the lesion epicenter, and rostral and caudal to it within $4 \mathrm{~h}$ of injury [19]. From days to years after the initial trauma, apoptotic cell death continues, and scarring and demyelination accompany Wallerian degeneration. All these processes contribute to motor and sensory functional deficits [20, 21].

Many pharmacological agents have been reported to reduce secondary injury and to be neuroprotective in a variety of animal models; these include anti-inflammatory [22-24] and antiapoptotic agents [24, 25] and agents that elevate cyclic adenosine monophosphate (cAMP) [26, 27]. None has yet proved effective in ameliorating the effects of acute spinal cord injury in clinical trials in humans.

There is increasing evidence that the non-adenine-based purine guanosine acts as an intercellular signaling molecule. It is released from cells and has several diverse effects on cells in vivo and in vitro, particularly trophic effects modulating cellular growth, differentiation, and survival [28, 29]. Guanosine has a number of effects on various cell types that make it a good candidate to test as a neuroprotective agent in acute spinal cord injury since it might potentially interact with several steps of the biochemical and cellular cascade. It is neuroprotective [28-32] and stimulates nerve regeneration $[5,33]$. It also protects several cell types against apoptosis induced by a variety of agents such as staurosporine [34] and beta-amyloid [35] and has been reported to increase intracellular cAMP [36, 37]. Therefore, in the present study, we assessed whether guanosine might ameliorate tissue damage and enhance functional outcome after acute spinal cord injury.

\section{Materials and methods}

Animals

Adult female Wistar rats (280-300 g body weight, Charles River) were maintained in a temperature-controlled vivarium on a 12:12-h light-dark cycle with food and tap water freely available. Rats were handled daily for 2 weeks before surgery.

Spinal cord injury induction and experimental design

Spinal cords were surgically exposed and compressed with modified coverslip forceps to produce a moderate traumatic spinal cord injury $[5,38]$. Before surgery, rats were given 
buprenorphine $(0.03 \mathrm{mg} / \mathrm{kg}$ body weight, subcutaneously) for pain relief. They were then anesthetized with isoflurane (3-5\%): $\mathrm{O}_{2}(1 \mathrm{l} / \mathrm{min})$ and a laminectomy was performed at T11/T12 to expose the spinal cord that was then crushed with modified coverslip forceps [5, 38-40]. The forceps were closed slowly (over $2 \mathrm{~s}$ ) compressing a 5-mm length of the spinal cord to a thickness of $1.4 \mathrm{~mm}$ for $15 \mathrm{~s}$. The wound was closed by suturing the muscles and fat pad, and by clipping the skin with stainless steel clips. Postoperatively, the rats were kept quiet and warm.

To evaluate the effect of guanosine on acute phase SCI pathophysiology, we studied two groups of rats $(n=24)$ with SCI. After surgery and prior to treatment, behavioral tests were done for each rat. Two of the total 24 animals were excluded from the study because of incorrect injury (BBB score at the surgery day before treatment below 4 or above 7 ; in our experience, about $91 \%$ of rats with this degree of crush were within the range of 5 to 6 on the BBB scale at first day after injury [38]). The 22 rats were then randomly divided into two groups. Starting $4 \mathrm{~h}$ after surgery, rats received either daily intraperitoneal (i.p.) injections of $8 \mathrm{mg} / \mathrm{kg}$ guanosine or the same volume of saline containing $0.001 \mathrm{~N} \mathrm{NaOH}$ [5] for 2 weeks. On day 7 after injury one animal in the saline group was euthanized because of a severe bladder infection.

\section{Motor and sensory functional recovery assessment}

All rats were handled daily for 2 weeks preoperatively to acclimatize them to the handling and behavioral testing. After spinal cord compression, the locomotor behavior segmental reflexes and spinothalamic senses of the rats were assessed immediately prior to treatment (day 0 ) and on days $1,3,5,7,14,21$, and 28 after the injury. Five tests were used: an open field walking task [5, 41, 42], hind limb placing response $[38,40]$, foot orienting response $[38,40$, 43], an inclined plane test [38, 44, 45], and a hot plate test [46]. Behavioral analyses were performed by individuals who were blinded with respect to treatment groups.

An open field walking testing (OFWT) was used to assess the locomotor functional recovery of the hind limb. It was conducted in a child's circular plastic swimming pool $(1.3 \mathrm{~m}$ in diameter $[5,38])$. Cagemates (two animals) were placed in the center of the open field. They were observed for 5-min periods and scored for general locomotor ability using the standard BBB scale. The rats were rated on a scale of 0 to 21,0 being no function and 21 being normal. If the animal stopped moving for a minute, it was placed again in the center of the open field; otherwise it was left undisturbed for the duration of the 5-min test period.

Reflexes in the hind limbs were assessed with hind limb placing response (HLPR) and foot orienting response (FOR). They were each scored on a scale of 0 to 2,0 indicating no function and 2 indicating full function [38, 40, 43]. Half-scores were assigned if the behavioral response appeared intermediate. Hind limbs were scored separately for each measure. To assess HLPR, we grasped the hind foot between the thumb and forefinger, pulled backwards, and then released the foot. The placement of the foot on the table surface was then scored $[38,40]$. The FOR followed Gruner's [40] protocol modified from the previous descriptions of this reflex [43]. When a rat is raised and lowered by the tail, it shows a characteristic behavior of the hind legs. A normal rat spreads the toes of its hind leg wide apart and generally holds them apart for several seconds. After spinal cord injury, this response is sometimes lost completely, or reduced in magnitude.

The inclined plane test (IPT) measured the ability of the rats to maintain their position for $5 \mathrm{~s}$ on an inclined plane, covered by a rubber mat containing horizontal ridges (1 $\mathrm{mm}$ deep, spaced $3 \mathrm{~mm}$ apart, self-made) [44]. The rats were observed as the angle of the surface was increased from 5 to $90^{\circ}$ at $5^{\circ}$ intervals. The angle at which the rat could no longer stay in position was the outcome measure.

Hind limb sensory function was tested by ability to perceive a standard application of a controlled stimulus to the trunk below the level of the lesion using a standard testing apparatus hot plate (IITC Life Science Inc., Woodland Hills, CA, USA) [46]. The time taken for the rat to withdraw its hind paws from contact with the hot plate was noted. A cutoff time was about $20 \mathrm{~s}$ after which the animals were removed to prevent thermal injury [46].

\section{Recovery of lower urinary tract function}

Normal lower urinary tract (LUT) function involves both spinal and supraspinal circuitry that controls urine storage and release [47]. Incomplete SCI results in an initial loss and later partial or complete recovery of LUT function depending on the severity of injury [48, 49].

After SCI the rats were not capable initially of spontaneous micturition, and their bladders were manually expressed twice daily. The volume of expressed urine was measured each time, and the data were used to estimate the initiation of LUT function after SCI.

\section{Histological analysis}

Tissue processing and immunohistochemical staining Twenty-eight days after SCI, animals were killed for histological and immunohistochemical analysis. Rats were deeply anesthetized with sodium pentobarbital $(50-60 \mathrm{mg} / \mathrm{kg}$ b/w, i.p.) and perfused transcardially; first with $100 \mathrm{ml} 0.05 \mathrm{M}$ phosphate-buffed saline (PBS) containing $0.1 \%$ heparin, followed by $300-500 \mathrm{ml}$ of $4 \%$ paraformaldehyde (PFA). The T9 to L1 segments of the spinal cords were removed and 
incubated in the same fixative solution overnight at $4{ }^{\circ} \mathrm{C}$ and then cryoprotected in PBS solution containing 30\% sucrose. A segment of each cord, extending from $5 \mathrm{~mm}$ rostral to $5 \mathrm{~mm}$ caudal to the lesion site was embedded in medium (Tissue-Tek ${ }^{\circledR}$ O.C.T. compound, Sakura Finetek USA, Inc., Torrrance, CA, USA). Serial sections were cut at $20-\mu \mathrm{m}$ intervals on a cryostat and mounted onto slides (ColorFrost/Plus; Fisher, Pittsburgh, PA, USA) for histochemical staining. Some cords were transverse-sectioned for immunohistochemical analysis using the antibodies described in the section below. Longitudinal sections were cut for Luxol fast blue staining, a lipophilic dye used commonly to stain myelin [38].

Details of these immunohistochemical procedures have been described previously $[5,38]$. Briefly, the cryostat sections were thawed, air-dried, and then incubated in hydrogen peroxide to reduce endogenous peroxidase activity, before being rinsed in PBS. The sections were then incubated in 1\% sodium borohydride for $15 \mathrm{~min}$. After thorough washing with PBS, the sections were treated with $\mathrm{PBS} / 5 \%$ normal goat serum with $0.3 \%$ Triton $\mathrm{X}-100$ at room temperature for $30 \mathrm{~min}$. Overnight incubation with primary antibody was performed in humidified boxes at $4^{\circ} \mathrm{C}$. Macrophages and reactive microglia were detected with a mouse monoclonal antibody against ED-1 (MCA 341R, 1:500; Serotec, Hornby, ON, Canada) and reactive astrocytes (astrogliosis) were determined with rabbit antiglial fibrillary acidic protein (GFAP) polyclonal antibodies (Zymed $^{\circledR}$ Lab-SA System Kit, dilution was 1:600, Invitrogen Canada Inc., Burlington, ON, Canada). The following day, sections were rinsed with PBS and incubated with either rhodamine-conjugated or fluorescein isothiocyanate (FITC)-conjugated secondary antibodies. Sections were then rinsed, coverslipped, and examined under a confocal microscope.

To determine the spared axons and myelin, double fluorescent immunolabeling was performed, combining mouse monoclonal antibodies against neurofilament (RT97, 1:10; Developmental Hybridoma Bank) and rabbit antimyelin basic protein (MBP) polyclonal antibodies (1:50; Chemicon Int., Temecula, CA, USA). For double immunolabeling, sections were developed using a mixture of FITCconjugated goat anti-rabbit IgG and rhodamine-conjugated goat anti-mouse $\mathrm{IgG}$ in $1 \%$ normal goat serum and $0.25 \%$ Triton X-100; 1:200 (Invitrogen Canada Inc., Burlington, ON, Canada) for $2 \mathrm{~h}$. Sections were then rinsed, coverslipped, and examined under a confocal microscope. An investigator who was blinded to the treatment groups conducted histological analysis.

Terminal deoxynucleotidyl transferase (TdT)-mediated dUTP-biotin nick end labeling assays and quantification For detection of apoptotic cells, a terminal deoxynucleotidyl transferase (TdT)-mediated dUTP nick end labeling (TUNEL) stain was performed using the "In situ Cell Death Detection Kit-Fluorescein" (Roche Molecular Biochemicals, Chemicon Int., Temecula, CA, USA), according to the manufacturer's instructions. After fixation, tissue sections were incubated in TdT-mediated dUTP-biotin nick end labeling (TUNEL) reaction mixture containing TdT buffer with TdT and biotinylated dUTP in TdT buffer, incubated in a humid atmosphere at $37^{\circ} \mathrm{C}$ for $90 \mathrm{~min}$, and then washed with PBS. The sections were incubated at room temperature $\left(37^{\circ} \mathrm{C}\right)$ for $30 \mathrm{~min}$ with fluorescenceconjugated antibody. The results were analyzed using confocal fluorescence microscopy. TUNEL-positive cells in the lesion site in the spinal cord were quantified by counting positively stained cells. Sections (5-7 per animal) taken from the penumbra of the lesion and spaced about $100 \mu \mathrm{m}$ apart were analyzed for each animal $(n=3-5$ animals per group). Apoptotic cell death was determined by counting the total number of TUNEL-positive nuclei through entire cross sections. Low power sections were digitized and manually outlined using an image analysis system. Any cavities present in the sections were excluded from analysis. Data are expressed as cells per section [5].

Quantification For cell counting, 5-7 sections from each animal ( $n=5$ for each group) at the lesion site (every third section, $100 \mu \mathrm{m}$ apart) were analyzed. OX-42-positive microglia and TUNEL-positive nuclei were counted through the entire cross section. Data are expressed as the number of immunostained cells per section (mean \pm SEM).

\section{Statistical analysis}

All data are presented as mean \pm SEM. The statistical significance of behavioral scores was analyzed by KruskalWallis nonparametric analysis of variance followed by Mann-Whitney U tests. Histological data were evaluated by Student's $t$-tests.

\section{Results}

Guanosine improves neurological function

Over the course of 4 weeks after spinal cord injury, control rats (which received saline treatment) recovered occasional weight-supported plantar steps, but no fore-hind limb coordination, and had a mean BBB locomotor score of $9.3 \pm 0.6$ (Fig. 1). In contrast, the guanosine-treated rats recovered to a BBB score of $14 \pm 0.5$ (Fig. 1); they exhibited consistent weight supporting with consistent fore-hind limb coordination. Hind limb locomotor function in guanosine- 
treated animals was significantly better than in rats that received saline treatment $(P<0.01)$.

Uninjured rats have normal HLPR scores of $2[38,40]$; they always place an extended hind limb briskly beneath the body in a proprioceptive placing response. Injured rats place their hind limb either partially, or unreliably, or not all, depending on the time since the injury and the treatment. In the present study, 4 weeks after injury, control rats with saline injection attained a $1.0 \pm 0.1$ HLPR score (Fig. 2) that was characterized by little or no attempt to place the foot, or leaving the foot extended with its dorsal surface down. In contrast, rats treated with guanosine reached a score of $1.7 \pm$ 0.1 (Fig. 2), with the toes of their hind legs spread wide apart, a finding which is significantly better than rats that received saline treatment $(P<0.01)$. Uninjured rats have a normal FOR score of 2. Saline-treated animals had a FOR score of $1.0 \pm 0.1$ (Fig. 3). These rats extended their hind legs laterally with toe spread but turned their feet outward. When these rats were lowered, they did not orient their feet toward the surface. In contrast, the guanosine-treated rats recovered to a score of $1.7 \pm 0.1$ (Fig. 3), which is significantly different $(P<0.01)$ from the saline-treated rats.

Uninjured rats maintain their position on the inclined plane even at an angle of $90^{\circ}$. In the present study, salinetreated control rats recovered their ability to maintain their position at $69^{\circ} \pm 2$ by 4 weeks after injury, whereas guanosine-treated rats were able to maintain their position to a mean incline of $79^{\circ} \pm 1$ (Fig. 4$)$ by 4 weeks $(P<0.05)$.

Both saline- and guanosine-treated rats were insensitive to the thermal stimulus using the hot plate test during the first 2 days after injury. There was a gradual recovery of sensory

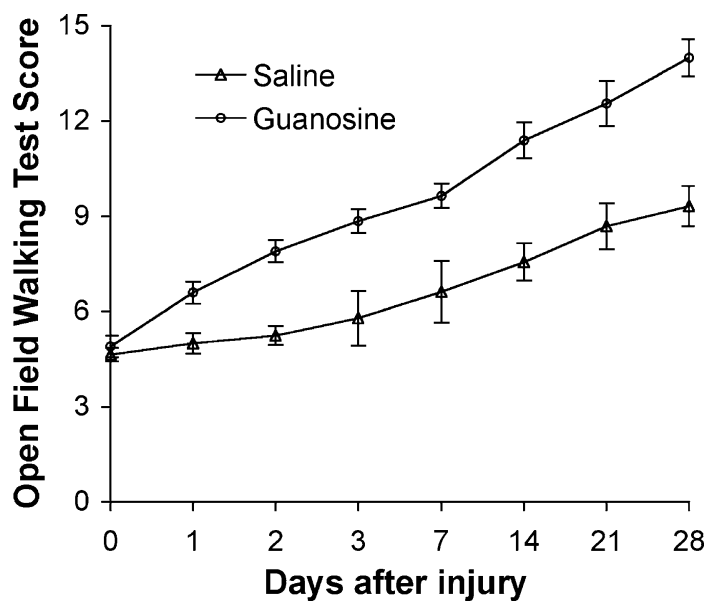

Fig. 1 Open field walking test (OFWT) scores from day 0 (the same day as surgery, prior to treatment) to 28 days after spinal cord injury for groups of saline- and guanosine-treated animals (means \pm SEM). Animals with normal spinal cord function score 21, whereas a score of 0 represents total paralysis. Hind limb locomotor function in guanosine-treated animals $(n=11)$ was significantly better than in rats that received saline treatment $(n=10 ; P<0.01)$ from day 1 to 28 after injury

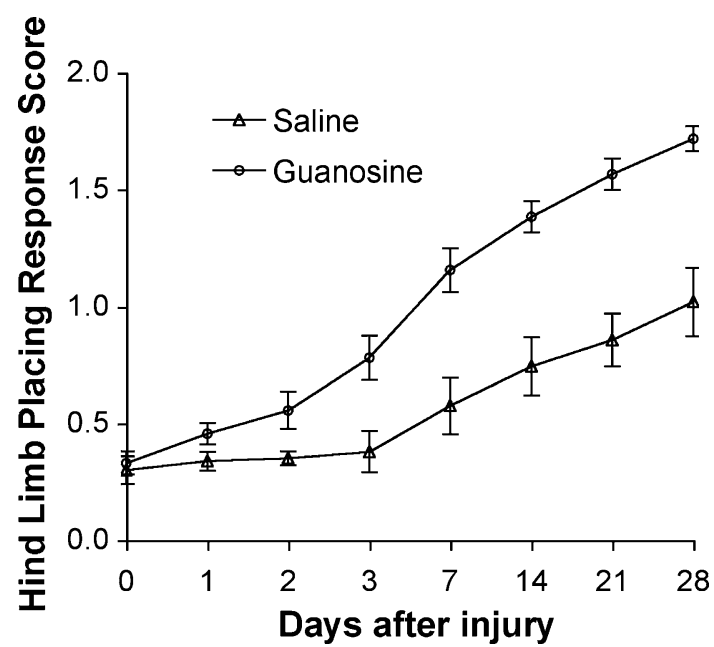

Fig. 2 Hind limb placing response (HLPR) scores from day 0 (the same day as surgery, prior to treatment) to 28 days after spinal cord injury for groups of saline- and guanosine-treated animals (means \pm SEM). Animals with normal spinal cord function score 2, whereas a score of 0 represents total paralysis. Compared with saline-treated control animals $(n=10)$, guanosine-treated animals $(n=11)$ had a significantly better improvement of their hind limb placing responses $(P<0.01)$ from day 1 to 28 after injury

function thereafter with recovery being accelerated in guanosine-treated animals compared to controls $(P<0.05)$ (Fig. 5).

\section{Guanosine accelerated LUT functional recovery} following SCI

In saline-treated rats the volume of manually expressed urine increased over the first 7 days after SCI and then

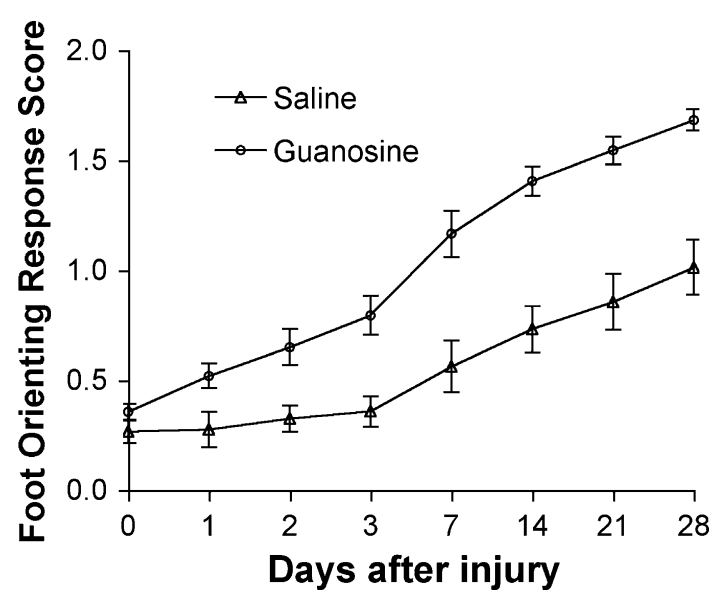

Fig. 3 Foot orienting response (FOR) scores from day 0 (the same day as surgery, prior to treatment) to 28 days after spinal cord injury for groups of saline- and guanosine-treated animals (means \pm SEM). Animals with normal spinal cord function score 2, whereas a score of 0 represents total paralysis. Compared with saline-treated control animals $(n=10)$, guanosine-treated animals $(n=11)$ had a significantly better improvement of their foot orienting responses $(P<0.01)$ from day 1 to 28 after injury 


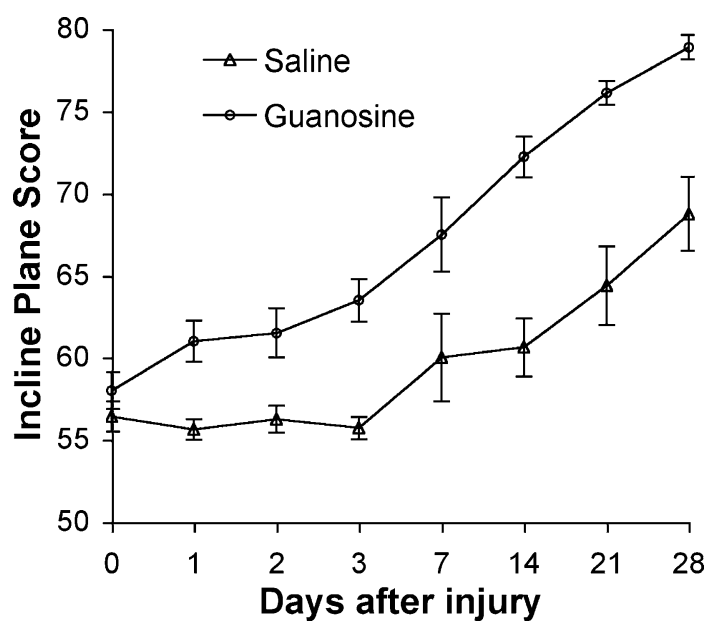

Fig. 4 Inclined plane test (IPT) scores from day 0 (the same day as surgery, prior to treatment) to 28 days after spinal cord injury for groups of saline- and guanosine-treated animals (means \pm SEM). Compared with saline-treated control animals $(n=10)$, guanosinetreated animals $(n=11)$ had a significantly better score in their inclined plane test $(P<0.05)$ from day 1 to 28 after injury

decreased as spontaneous micturition was reestablished. On the basis of a previous study [48], the increase in volume of expressed urine during the first week after injury was interpreted as resulting from increased bladder size in the absence of spontaneous micturition. The subsequent decrease in manually expressed urine indicates the initiation of spontaneous micturition (Fig. 6). In guanosine-treated rats there was a significantly lower residual urine volume compared to the saline-treated animals (Fig. 6; $P<0.001$ ). More importantly, the rats that received guanosine recov-

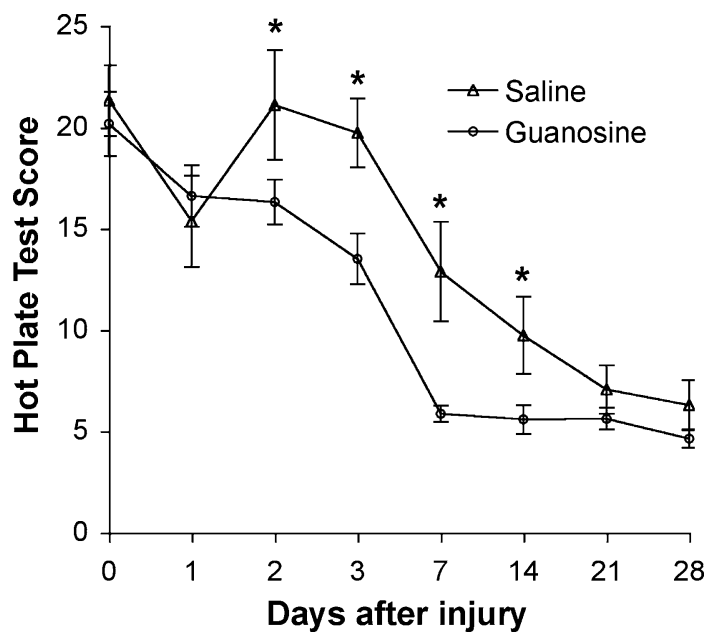

Fig. 5 Post-lesional sensitivity of hind limbs touched by a hot plate from day 0 (the same day as surgery, prior to treatment) to 28 days after spinal cord injury for groups of saline- and guanosine-treated animals. Values are the means \pm SEM of the average time of withdrawal of left and right hind paws during contact with a hot plate. Compared with saline-treated control animals $(n=10)$, guanosine-treated animals $(n=11)$ had a significantly better improvement of their sensory function $(* P<0.05)$ from day 2 to 14 after injury ered their LUT function completely by 7 days after injury (Fig. 6).

Guanosine attenuates macrophage and microglia activation, but not astrogliosis

After SCI, early inflammatory reactions consisting of neutrophil and macrophage invasion as well as activation of microglia and astrocytes were reported in earlier studies $[50,51]$. In the present study, the activated macrophages and microglia were labeled by the ED-1 immunoreaction. Guanosine treatment decreased the number of the ED-1 immunopositive cells compared with saline treatment (Fig. 7a, b, e; $P<0.01$ ). However, no differences were found between the saline and guanosine groups in the number of activated astroglia (astrogliosis) indicated by the GFAP immunostaining (Fig. 7c, d).

Guanosine attenuates apoptotic cell death in lesion site of spinal cord

In the present study, apoptotic cell death induced by traumatic spinal cord injury was determined with TUNEL staining. TUNEL-positive nuclei were not uniformly distributed throughout the cross section of the spinal cord but were more numerous in the vicinity of the injury center. Quantification of TUNEL-positive nuclei showed that there were significantly fewer TUNEL-positive nuclei in the spinal cords of guanosine-treated rats than saline-treated control animals (Fig. $8 ; P<0.001$ ).

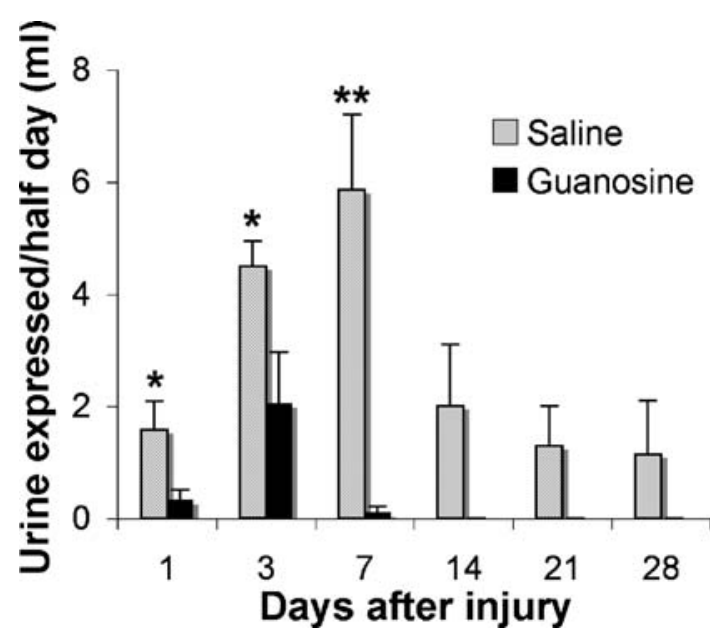

Fig. 6 Time course of recovery of lower urinary tract function (spontaneous voiding). Urinary bladders were expressed every $12 \mathrm{~h}$, and the collected urine volume was measured. Means \pm SEM of the volume for each group. Compared with saline-treated control animals $(n=10)$, guanosine-treated animals $(n=11)$ had significantly less urine collected with time after SCI $(* P<0.05 ; * * P<0.001)$. The rats that received guanosine had empty bladders by day 7 after injury 

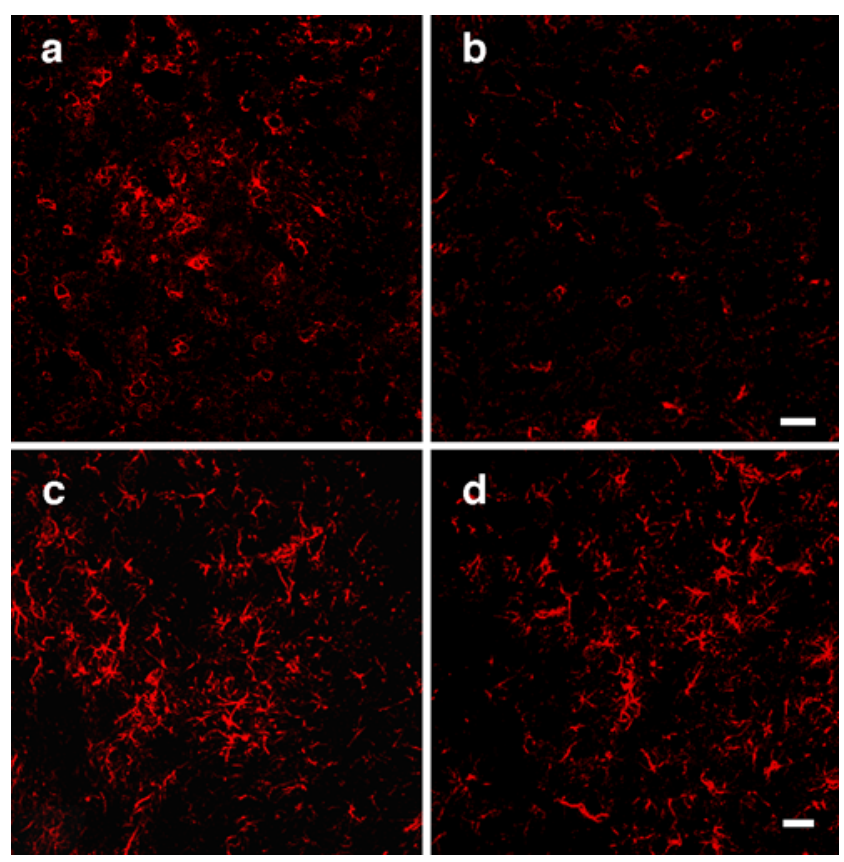

e

$p<0.01$

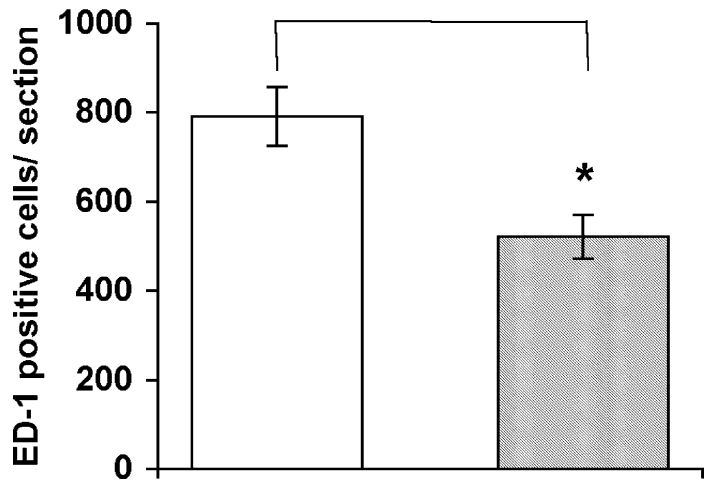

$\square$ Vehicle control $\square$ Guanosine

Fig. 7 Fluorescent immunostaining using antibodies against a marker (ED-1) for macrophages and activated microglia in cross sections of cords from saline-treated (a) and guanosine-treated (b) animals at the lesion site 4 weeks after injury. There were fewer ED-1-immunolabeled cells in cords of guanosine-treated rats $(\mathbf{b}, \mathbf{e})$ compared to the cords of vehicle-treated rats (a, e; $P<0.01)$. GFAP-immunofluorescent staining of cross sections of spinal cords from vehicle-treated (c) and guanosine-treated (d) animals at the lesion site 4 weeks after injury showed no difference in immunostaining of GFAP between the cords of guanosine-treated rats (d) and vehicle-treated rats (c). Scale bar= $50 \mu \mathrm{m}$ for all

\section{Guanosine increases axon and myelin sparing}

Axons were labeled with antibodies against RT-97 (a neuronal cytoskeletal protein; Fig. 9a, b) and myelin was labeled with antibodies against MBP (a specific marker for myelin; Fig. 9c, d). The immunohistochemistry showed that there were more axons (red, Fig. 9b) and myelin (green, Fig. 9d) as well as myelinated axons (yellow, Fig. 9f) in the spinal cords from guanosine-treated animals than in the cords from saline-treated control rats (Fig. 9a, c, e), indicating that systemic administration of guanosine is associated with preservation of tissue including neuronal and glial elements.

\section{Discussion}

These data are the first to demonstrate the ability of guanosine to act as a neuroprotective agent in vivo. These findings have potential clinical relevance. Previous studies have shown that after central nervous system injuries, the concentrations of guanosine are elevated around the injury and in CSF, sometimes for prolonged periods [32, 52]. Given the various trophic and antiapoptotic effects of guanosine in vitro [28, 34, 35], it seemed likely that increasing the concentration of guanosine in the central nervous system after injury in vivo might also be neuroprotective. We found that within $7 \mathrm{~min}$ of systemic administration, guanosine enters and progressively accumulates in the central nervous system (unpublished data), where it is converted to guanine. It remains to be determined whether guanosine, guanine, or both are the active neuroprotective agent. However, guanosine is more readily deliverable than guanine as a potential neuroprotectant.

The model of incomplete spinal cord injury that we have used is clinically relevant since about $50 \%$ of patients with spinal trauma have incomplete injury [53]. After incomplete spinal cord injury, both reflex and voluntary motor functions below the level of the injury are initially lost; partial recovery occurs over time $[41,54,55]$. The recovery of functions mediated by supraspinally controlled reflexes is slow and incomplete since these require the function of long tracts, many of which are irreversibly damaged by the injury [56, 57]. Recovery of locomotion and limb placement depends on ascending and descending spinal cord tracts, including cortico-, rubro-, reticulo-, vestibulo-, and raphespinal tracts [58]. The functional loss after spinal cord injury in rats involves interruption of descending serotonergic [59], reticulospinal, and other descending spinal tracts that facilitate segmental reflexes [40, 60]. The ascending spinothalamic tracts mediate the perception of pain and temperature below the level of the lesion. Since all of these motor and sensory functions were better in guanosine-treated animals than in control animals, it appears that guanosine preserved the function of multiple long tracts. This was associated with increased axonal survival and myelin preservation.

Normal micturition requires coordinated activation of the bladder smooth muscle (detrusor) and the striated muscle of the external urethral sphincter, controlled by spinal and supraspinal circuitry [47]. Thus after incomplete spinal cord injury, initially bladder function is lost, but later partially 
Fig. 8 TUNEL-positive apoptotic cells in spinal cord lesions were quantified by counting the total number of TUNEL-positive nuclei through entire cross sections. Compared with the cords from saline-treated animals $(\mathbf{a}, \mathbf{c})$, guanosine-treated cords had significantly fewer TUNEL-positive cells $(\mathbf{b}, \mathbf{c} ; P<0.001)$. Scale bar $=$ $50 \mu \mathrm{m}$ for both $\mathbf{a}$ and $\mathbf{b}$
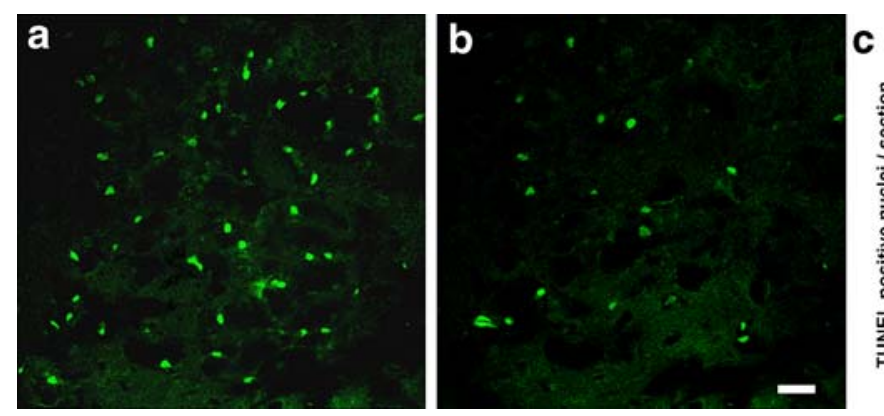

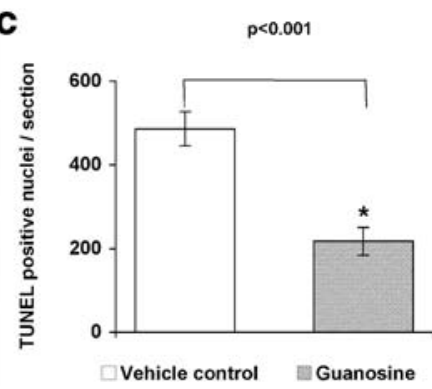

recovers, the extent of recovery depending on the degree of preservation of white matter (and hence the long tracts) at the injury site $[48,49]$. Our data revealed that in guanosinetreated rats, residual urine volume was not only much less
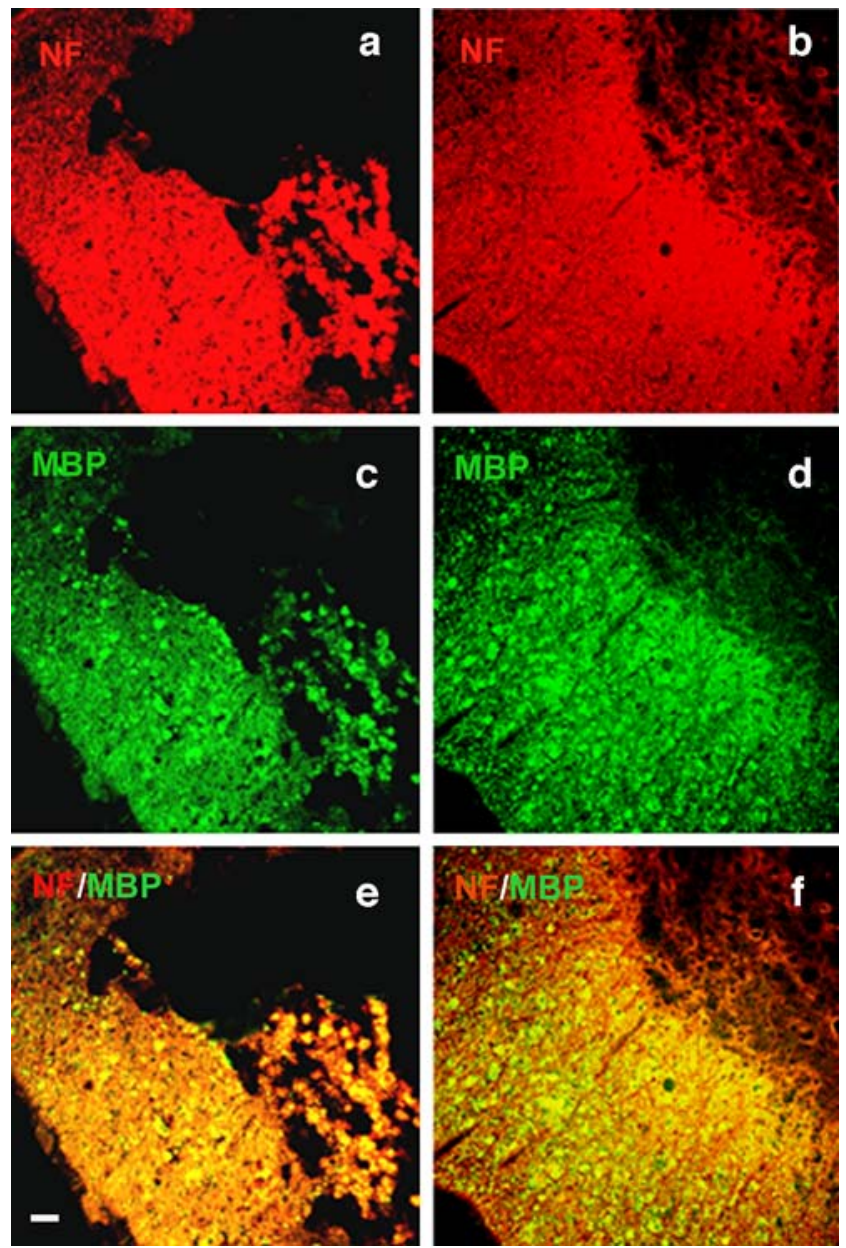

Fig. 9 Immunostaining with antibodies against RT-97 for labeling axons (a, b) and against myelin basic protein (MBP) for central myelin (c, d) at the lesion site demonstrated the spared tissue. Cross sections from saline-treated (a) and guanosine-treated cords (b) demonstrate a neurofilament $(N F)$ immunoreactivity surrounding the lesion site. c, d Cross sections from saline-treated (c) and guanosinetreated cords reveal myelin at the lesion site. e, $\mathbf{f}$ Merger of the two images demonstrates NF (red) and MBP (green) double fluorescent immunolabeling. There were more spared axons and more myelin in the cords around the lesion site from guanosine-treated animals compared to the saline-treated group. Scale bar $=50 \mu \mathrm{m}$ for all than in controls from the first day after the spinal cord injury, but that by 7 days after spinal cord injury micturition had returned to normal. Because guanosine began to exert a neuroprotective effect on both motor and bladder function soon after it was first administered, its neuroprotective effect on each may involve similar mechanisms.

The inherent complexity of the biological system coupled with the many potential trophic actions of guanosine make it difficult to determine the mechanisms by which guanosine produces its effects. Nevertheless, neuroprotective effects were observed by $24 \mathrm{~h}$ after spinal cord injury. As guanosine was administered $4 \mathrm{~h}$ postinjury, it must have affected processes that were important between 4 and $24 \mathrm{~h}$ post-injury. Within this time frame after traumatic injury of the spinal cord, both inflammatory responses and apoptosis are prominent. Activation and proliferation of microglia/macrophages play an important role in the secondary damage following spinal cord injury. Thus, cells at the center of the injury cascade are potential targets for neuroprotective treatments of acute SCI $[21,61]$. As guanosine attenuated the activation and proliferation of microglia/macrophages following SCI, this may at least in part provide an explanation for its neuroprotective effect.

Guanosine has antiapoptotic effects in vitro [34, 35] and this is another potential mechanism through which guanosine might exert beneficial effects after spinal cord injury. Apoptosis after SCI has been described by many investigators [15, 62-67]. In these reports, early apoptosis of neural cells, including neurons, is followed by a delayed wave of predominantly oligodendroglial-programmed cell death in degenerating white matter tracts [63-67]. Studies of apoptosis in white matter after injury raise the possibility that glial apoptosis occurs, at least in part, as a consequence of axonal degeneration $[68,69]$. However, the presence of activated microglia in contact with apoptotic oligodendrocytes after SCI indicates that this interaction may also activate cell death programs in the oligodendrocyte [70]. Secondary axonal degeneration may then follow [71, 72]. In the present study, guanosine significantly suppressed apoptosis in the injured spinal cords when it was systemically administered daily for 2 weeks beginning $4 \mathrm{~h}$ after injury. It seems reasonable to postulate that decreasing 
apoptosis may be an important mechanism through which guanosine improves neurological outcome after SCI.

Although the intracellular pathways through which guanosine suppresses apoptotic cell death following spinal cord injury are not known, a number of intracellular pathways which protect cells against apoptosis have been identified. These include the phosphatidylinositol 3-kinase (PI-3-K)/Akt/protein kinase B (PKB) pathway [73, 74] and the mitogen-activated protein (MAP) kinase pathway [75]. Our previous studies in vitro have shown that the antiapoptotic effect of guanosine is mediated by the activation of both PI-3-K/Akt/PKB and MAPK pathways $[34,35]$.

Guanosine can also increase intracellular cAMP in various cell types [36, 37], and increases in cAMP after spinal cord injury have been shown to increase recovery $[26,27]$. However, it appears unlikely that increases in intracellular cAMP are responsible for the effects of guanosine since the principal effect of cAMP in enhancing recovery from spinal cord injury appears to be due to its ability to promote axonal regeneration. In contrast, the neuroprotective effects we observed early after administration of guanosine are unlikely to be explained on the basis of outgrowth of damaged axons. A much longer time frame could be required for this to occur.

A further possible mechanism by which guanosine might exert its neuroprotective effects is by stimulating cells to release and increase synthesis of various trophic factors, such as basic fibroblast growth factor (bFGF), nerve growth factor (NGF), and neurotrophin-3 (NT-3) [28]. Such trophic factors can contribute to tissue preservation after trauma [67]. The ability of guanosine to stimulate production and release of trophic factors may not only have early effects, but also may contribute to the reduced number of apoptotic cells observed 3 weeks after the injury.

This study is important not only because it is the first to demonstrate the neuroprotective effect of systemically administered guanosine in acute spinal cord injury, but also because it indicates some of the potential mechanisms whereby guanosine may exert its neuroprotective effects in vivo. This work provides a basis for further exploration of the purinergic mechanisms underlying the neuroprotective effects of exogenous guanosine. Furthermore, and of potential clinical importance, is that guanosine was effective when it was administered $4 \mathrm{~h}$ after the injury-a realistic time frame in which to initiate treatment after spinal cord injury in humans.

Acknowledgements We thank Dr. Raelene Kinlough-Rathbone for her helpful suggestions and critical appraisal of the manuscript. Shucui Jiang is recipient of a Chris Beehler Faculty Investigator Award from the Canadian Spinal Research Organization.

\section{References}

1. Ackery A, Tator C, Krassioukov A (2004) A global perspective on spinal cord injury epidemiology. J Neurotrauma 21:1355-1370

2. Schwab ME, Bartholdi D (1996) Degeneration and regeneration of axons in the lesioned spinal cord. Physiol Rev 76:319-370

3. Hulsebosch CE (2002) Recent advances in pathophysiology and treatment of spinal cord injury. Adv Physiol Educ 26:238-255

4. Nath M, Wheeler JS Jr, Walter JS (1993) Urologic aspects of traumatic central cord syndrome. J Am Paraplegia Soc 16:160-164

5. Jiang S, Khan MI, Lu Y, Wang J, Buttigieg J, Werstiuk ES, Ciccarelli R, Caciagli F, Rathbone MP (2003) Guanosine promotes remyelination and functional recovery in chronic spinal injury. Neuroreport 14:2463-2467

6. Tator CH (1995) Update on the pathophysiology and pathology of acute spinal cord injury. Brain Pathol 5:407-413

7. Sandler AN, Tator CH (1976) Review of the effect of spinal cord trauma on the vessels and blood flow in the spinal cord. J Neurosurg 45:638-646

8. Kobrine AI (1975) The neuronal theory of experimental traumatic spinal cord dysfunction. Surg Neurol 3:261-264

9. Anderson DK, Hall ED (1993) Pathophysiology of spinal cord trauma. Ann Emerg Med 22:987-992

10. Omura T, Omura K, Sano M, Sawada T, Hasegawa T, Nagano A (2005) Spatiotemporal quantification of recruit and resident macrophages after crush nerve injury utilizing immunohistochemistry. Brain Res 1057:29-36

11. Popovich PG, Wei P, Stokes BT (1997) Cellular inflammatory response after spinal cord injury in Sprague-Dawley and Lewis rats. J Comp Neurol 377:443-464

12. Taoka Y, Okajima K, Uchiba M, Murakimi K, Kushimoto S, Johno M, Nauro M, Okabe H, Takatsuki K (1997) Role of neutrophils in spinal cord injury in the rat. Neuroscience 79:1177-1182

13. Carlson SL, Parrish ME, Springer JE, Doty K, Dossett L (1998) Acute inflammatory response in spinal cord following impact injury. Exp Neurol 151:77-88

14. Rice T, Larsen J, Rivest S, Yong VW (2007) Characterization of the early neuroinflammation after spinal cord injury in mice. $\mathrm{J}$ Neuropathol Exp Neurol 66:184-195

15. Beattie MS, Hermann GE, Rogers RC, Bresnahan JC (2002) Cell death in models of spinal cord injury. Prog Brain Res 137:37-47

16. Scott GS, Jakeman LB, Stokes BT, Szabo C (1999) Peroxynitrite production and activation of poly (adenosine diphosphate-ribose) synthetase in spinal cord injury. Ann Neurol 45:120-124

17. Liu D, Ling X, Wen J, Liu J (2000) The role of reactive nitrogen species in secondary spinal cord injury: formation of nitric oxide, peroxynitrite, and nitrated protein. J Neurochem 75:2144-2154

18. Xu J, Kim GM, Chen S, Yan P, Ahmed SH, Ku G, Beckman JS, Xu XM, Hsu CY (2001) iNOS and nitrotyrosine expression after spinal cord injury. J Neurotrauma 18:523-532

19. Grossman SD, Rosenberg LJ, Wrathall JR (2001) Temporalspatial pattern of acute neuronal and glial loss after spinal cord contusion. Exp Neurol 168:273-282

20. Taoka Y, Okajima K (1998) Spinal cord injury in the rat. Prog Neurobiol 56:341-358

21. Hagg T, Oudega M (2006) Degenerative and spontaneous regenerative processes after spinal cord injury. J Neurotrauma 23:264-280

22. Teng YD, Choi H, Onario RC, Zhu S, Desilets FC, Lan S, Woodard EJ, Snyder EY, Eichler ME, Friedlander RM (2004) Minocycline inhibits contusion-triggered mitochondrial cytochrome c release and mitigates functional deficits after spinal cord injury. Proc Natl Acad Sci U S A 101:3071-3076

23. Scott GS, Cuzzocrea S, Genovese T, Kopriwski H, Hooper DC (2005) Uric acid protects against secondary damage after spinal cord injury. Proc Natl Acad Sci U S A 102:3483-3488 
24. Kyung KS, Gon JH, Geun KY, Sup JJ, Suk WJ, Ho KJ (2006) 6Shogaol, a natural product, reduces cell death and restores motor function in rat spinal cord injury. Eur J Neurosci 24:1042-1052

25. Casha S, Yu WR, Fehlings MG (2005) FAS deficiency reduces apoptosis, spares axons and improves function after spinal cord injury. Exp Neurol 196:390-400

26. Nikulina E, Tidwell JL, Dai HN, Bregman BS, Filbin MT (2004) The phosphodiesterase inhibitor rolipram delivered after a spinal cord lesion promotes axonal regeneration and functional recovery. Proc Natl Acad Sci U S A 101:8786-8790

27. Lu P, Yang H, Jones LL, Filbin MT, Tuszynski MH (2004) Combinatorial therapy with neurotrophins and cAMP promotes axonal regeneration beyond sites of spinal cord injury. J Neurosci 24:6402-6409

28. Rathbone MP, Middlemiss PJ, Gysbers JW, Andrew C, Herman MAR, Reed JK, Ciccarelli R, Di Iorio P, Caciagli F (1999) Trophic effects of purines in neurons and glia cells. Prog Neurobiol 59:663-690

29. Di Iorio P, Caciagli F, Giuliani P, Ballerini P, Ciccarelli R, Sperling O, Zoref-Shani E, Benowitz L, Traversa U, Bombi G, Florio T, Virgilio A, Andrew CM, Crocker CE, Werstiuk ES, Middlemiss PJ, Rathbone MP (2001) Purine nucleosides protect injured neurons and stimulate neuronal regeneration by intracellular and membrane receptor-mediated mechanisms. Drug Dev Res 52:303-315

30. Ballerini P, Di Iorio P, Caciagli F, Rathbone MP, Jiang S, Nargi E, Buccella S, Giuliani P, D’Alimonte I, Fischione G, Masciulli A, Romano S, Ciccarelli R (2006) P2Y2 receptor up-regulation induced by guanosine or UTP in rat brain cultured astrocytes. Int J Immunopathol Pharmacol 19:293-308

31. D'Alimonte I, Flati V, D'Auro M, Toniato E, Martinotti S, Rathbone MP, Jiang S, Ballerini P, Caciagli F, Ciccarelli R (2007) Guanosine inhibits CD40 receptor expression and function induced by cytokines and $\beta$ amyloid in mouse microglia cells. J Immunol 178:720-731

32. Loeffler DA, LeWitt PA, Juneau PL, Camp DM, DeMaggio AJ, Milburg P, Matson WR, Rathbone MP (1998) Altered guanosine and guanine concentrations in rabbit striatum following increased dopamine turnover. Brain Res Bull 45:297-299

33. Bau C, Middlemiss PJ, Jiang S, Hindley S, Ciccarelli RS, Caciagli F, Dilorio P, Werstiuk ES, Rathbone MP (2005) Guanosine stimulates neurite outgrowth in PC12 cells via activation of heme oxygenase and cyclic GMP. Purinergic Signalling 1:161-172

34. Di Iorio P, Ballerini P, Traversa U, Nicoletti F, D'Alimonte I, Kleywegt S, Werstiuk ES, Rathbone MP, Caciagli F, Ciccarelli R (2004) The antiapoptotic effect of guanosine is mediated by the activation of the PI 3-kinase/AKT/PKB pathway in cultured rat astrocytes. Glia 46:356-368

35. Pettifer KM, Kleywegt S, Bau CJ, Ramsbottom JD, Vertes E, Ciccarelli R, Caciagli F, Werstiuk ES, Rathbone MP (2004) Guanosine protects SH-SY5Y cells against beta-amyloid-induced apoptosis. Neuroreport 15:833-836

36. Rathbone MP, Middlemiss PJ, DeLuca B, Jovetich M (1991) Extracellular guanosine increases astrocyte cAMP: inhibition by adenosine A2 antagonists. Neuroreport 2:661-664

37. Gysbers JW, Rathbone MP (1996) Neurite outgrowth in PC12 cells is enhanced by guanosine through both cAMP-dependent and -independent mechanisms. Neurosci Lett 220:175-178

38. Jiang S, Khan MI, Middlemiss PJ, Lu Y, Werstiuk ES, Crocker CE, Ciccarlli R, Caciagli F, Rathbone MP (2004) AIT-082 and methylprednisolone singly, but not in combination, enhance functional and histological improvement after acute spinal cord injury in rats. Int J Immunopathol Pharmacol 17:353-366

39. Blight AR (1991) Morphometric analysis of a model of spinal cord injury in guinea pigs, with behavioral evidence of delayed secondary pathology. J Neurol Sci 103:156-171
40. Gruner JA, Yee AK, Blight AR (1996) Histological and functional evaluation of experimental spinal cord injury: evidence of a stepwise response to graded compression. Brain Res 729:90-101

41. Basso DM, Beattie MS, Bresnahan JC (1995) A sensitive and reliable locomotor rating scale for open field testing in rats. $\mathrm{J}$ Neurotrauma 12:1-21

42. Basso DM, Beattie MS, Bresnahan JC (1996) Graded histological and locomotor outcomes after spinal cord contusion using the NYU weight-drop device versus transection. Exp Neurol 139:244-256

43. Kerasidis H, Wrathall JR, Gale K (1987) Behavioral assessment of functional deficit in rats with contusive spinal cord injury. $\mathrm{J}$ Neurosci Methods 20:167-179

44. Rivlin AS, Tator CH (1977) Objective clinical assessment of motor function after experimental spinal cord injury in the rat. $\mathrm{J}$ Neurosurg 47:577-581

45. Bresnahan JC, Beattie MS, Todd FD III, Noyes DH (1987) A behavioral and anatomical analysis of spinal cord injury produced by a feedback-controlled impaction device. Exp Neurol 95:548-570

46. Lopez S, Dadure C, Vergnes C, Capdevila X (2006) Intrathecal bupivacaine protects against extension of lesions in an acute contusive spinal cord injury model. Eur J Anaesthesiol 23:793-800

47. de Groat WC (1990) Central neural control of the lower urinary tract. Ciba Found Symp 151:27-44; discussion 44-56

48. Pikov V, Gillis RA, Jasmin L, Wrathall JR (1998) Assessment of lower urinary tract functional deficit in rats with contusive spinal cord injury. J Neurotrauma 15:375-386

49. Pikov V, Wrathall JR (2001) Coordination of the bladder detrusor and the external urethral sphincter in a rat model of spinal cord injury: effect of injury severity. J Neurosci 21:559-569

50. Dusart I, Schwab ME (1994) Secondary cell death and the inflammatory reaction after dorsal hemisection of the rat spinal cord. Eur J Neurosci 6:712-724

51. Merola A, O'Brien MF, Castro BA, Smith DA, Eule JM, Lowe TG, Dwyer AP, Haher TR, Espat NJ (2002) Histologic characterization of acute spinal cord injury treated with intravenous methylprednisolone. J Orthop Trauma 16:155-161

52. Uemura Y, Miller JM, Matson WR, Beal MF (1991) Neurochemical analysis of focal ischemia in rats. Stroke 22:1548-1553

53. Bracken MB, Shepard MJ, Collins WF, Holford TR, Young W, Baskin DS, Eisenberg HM, Flamm E, Leo-Summers L, Maroon J et al (1990) A randomized, controlled trial of methylprednisolone or naloxone in the treatment of acute spinal-cord injury. Results of the Second National Acute Spinal Cord Injury Study. N Engl J Med 322:1405-1411

54. Gale K, Kerasidis H, Wrathall JR (1985) Spinal cord contusion in the rat: behavioral analysis of functional neurologic impairment. Exp Neurol 88:123-134

55. Ko HY, Ditunno JF Jr, Graziani V, Little JW (1999) The pattern of reflex recovery during spinal shock. Spinal Cord 37:402-409

56. Leis AA, Kronenberg MF, Stetkarova I, Paske WC, Stokic DS (1996) Spinal motoneuron excitability after acute spinal cord injury in humans. Neurology 47:231-237

57. Hiersemenzel LP, Curt A, Dietz V (2000) From spinal shock to spasticity: neuronal adaptations to a spinal cord injury. Neurology 54:1574-1582

58. Basso DM (2000) Neuroanatomical substrates of functional recovery after experimental spinal cord injury: implications of basic science research for human spinal cord injury. Phys Ther 80:808-817

59. Saruhashi Y, Young W (1994) Effect of mianserin on locomotory function after thoracic spinal cord hemisection in rats. Exp Neurol 129:207-216

60. Faden A, Salzman SK (1994) The neurobiology of central nervous system trauma. Oxford University Press, New York, pp 227-244

61. Tian DS, Xie MJ, Yu ZY, Zhang Q, Wang YH, Chen B, Chen C, Wang W (2007) Cell cycle inhibition attenuates microglia induced 
inflammatory response and alleviates neuronal cell death after spinal cord injury in rats. Brain Res 1135:177-185

62. Casha S, Yu WR, Fehlings MG (2001) Oligodendroglial apoptosis occurs along degenerating axons and is associated with FAS and p75 expression following spinal cord injury in the rat. Neuroscience 103:203-218

63. Crowe MJ, Bresnahan JC, Shuman SL, Masters JN, Beattie MS (1997) Apoptosis and delayed degeneration after spinal cord injury in rats and monkeys. Nat Med 3:73-76

64. Emery E, Aldana P, Bunge MB, Puckett W, Srinivasan A, Keane RW, Bethea J, Levi AD (1998) Apoptosis after traumatic human spinal cord injury. J Neurosurg 89:911-920

65. Liu XZ, Xu XM, Hu R, Du C, Zhang SX, McDonald JW, Dong HX, Wu YJ, Fan GS, Jacquin MF, Hsu CY, Choi DW (1997) Neuronal and glial apoptosis after traumatic spinal cord injury. J Neurosci 17:5395-5406

66. Yong C, Arnold PM, Zoubine MN, Citron BA, Watanabe I, Berman NE, Festoff BW (1998) Apoptosis in cellular compartments of rat spinal cord after severe contusion injury. J Neurotrauma 15:459-472

67. McDonald JW, Belegu V (2006) Demyelination and remyelination after spinal cord injury. J Neurotrauma 23:345-359

68. Abe Y, Yamamoto T, Sugiyama Y, Watanabe T, Saito N, Kayama H, Kumagai T (1999) Apoptotic cells associated with Wallerian degener- ation after experimental spinal cord injury: a possible mechanism of oligodendroglial death. J Neurotrauma 16:945-952

69. Warden P, Bamber NI, Li H, Esposito A, Ahmad KA, Hsu CY, Xu XM (2001) Delayed glial cell death following wallerian degeneration in white matter tracts after spinal cord dorsal column cordotomy in adult rats. Exp Neurol 168:213-224

70. Shuman SL, Bresnahan JC, Beattie MS (1997) Apoptosis of microglia and oligodendrocytes after spinal cord contusion in rats. J Neurosci Res 50:798-808

71. Bjartmar C, Yin X, Trapp BD (1999) Axonal pathology in myelin disorders. J Neurocytol 28:383-395

72. Yin X, Crawford TO, Griffin JW, Tu P, Lee VM, Li C, Roder J, Trapp BD (1998) Myelin-associated glycoprotein is a myelin signal that modulates the caliber of myelinated axons. J Neurosci 18:1953-1962

73. Chan TO, Rittenhouse SE, Tsichlis PN (1999) AKT/PKB and other D3 phosphoinositide-regulated kinases: kinase activation by phosphoinositide-dependent phosphorylation. Annu Rev Biochem 68:965-1014

74. Cantley LC (2002) The phosphoinositide 3-kinase pathway. Science 296:1655-1657

75. Bonni A, Brunet A, West AE, Datta SR, Takasu MA, Greenberg ME (1999) Cell survival promoted by the Ras-MAPK signaling pathway by transcription-dependent and -independent mechanisms. Science 286:1358-1362 